\title{
Neuroendoscopic surgery in children: an analysis of 200 consecutive procedures
}

Neuroendoscopia em crianças: uma análise de 200 procedimentos consecutivos

Luciano Lopes Furlanetti1,2, Marcelo Volpon Santos ${ }^{1}$, Ricardo Santos de Oliveira ${ }^{1}$

\begin{abstract}
Objective: Neuroendoscopic surgery in children has particular features and is associated with different success rates (SR). The aim of this study was to identify putative factors that could influence the outcome in pediatric patients. Methods: Clinical data of 177 patients under 18 years of age submitted to 200 consecutive neuroendoscopic procedures from January 2000 to January 2010 were reviewed. Results: The overall success rate was $77 \%$. Out of the patients with successful outcomes, $46 \%$ were under six months, $68 \%$ were between six months and one year of age, and $85 \%$ older than one year. Neuroendoscopic techniques provide very good results for a wide number of indications in children. Tumor-related cerebrospinal fluid (CSF) circulation problems and aqueductal stenosis seem to be particularly well suited to neuroendoscopic treatment regardless of the patient's age. Conclusion: Patients' age and etiology of hydrocephalus were associated with a different outcome. In all cases, surgical experience is extremely important to reduce complications.
\end{abstract}

Key words: endoscopic third ventriculostomy, hydrocephalus, neuroendoscopy, pediatric neurosurgery.

\section{RESUMO}

Objetivo: A cirurgia neuroendoscópica em crianças apresenta particularidades e está associada a diferentes taxas de sucesso (TS). O objetivo deste estudo consistiu em identificar fatores que pudessem influir no resultado do tratamento em pacientes pediátricos. Métodos: Dados clínicos de 177 pacientes com idade inferior a 18 anos submetidos a 200 procedimentos neuroendoscópicos consecutivos entre janeiro de 2000 e janeiro de 2010 foram revisados. Resultados: A taxa de sucesso global foi de 77\%. Os pacientes com idade inferior a seis meses apresentaram taxa de sucesso de 46\%; pacientes entre seis meses e um ano de vida obtiveram êxito em 68\% dos casos; dentre os maiores de um ano, $85 \%$ dos procedimentos foram bem-sucedidos. Técnicas neuroendoscópicas proporcionam muito bons resultados para uma grande variedade de indicações em crianças. Independentemente da faixa etária, o tratamento endoscópico apresenta-se particularmente adequado para problemas da circulação liquórica relacionados a tumores e à estenose aquedutal. Conclusão: A faixa etária dos pacientes e a etiologia da hidrocefalia estão associadas a diferentes resultados. Em todos os casos, experiência neurocirúrgica é extremamente importante para a redução das complicações.

Palavras-Chave: terceiro ventriculostomia endoscópica, hidrocefalia, neuroendoscopia, neurocirurgia pediátrica.

The use of an endoscope to treat hydrocephalus has become a well-established technique that emerged in the early $20^{\text {th }}$ century when Sir Walter Dandy began treating hydrocephalus by endoscopically cauterizing or removing the choroid plexus ${ }^{1}$. In the past two decades, introduction of new instruments including rod lenses, Hopkins optic devices and high-resolution cameras has led to a huge increase in the number of neuroendoscopic procedures performed in specialized neurosurgical centers ${ }^{2,3}$.

Neuroendoscopy is particularly useful as an adjunct tool in the treatment of hydrocephalus. It is an attractive method owing to its simplicity, durability and because it does not require lifelong implanted hardware ${ }^{4,5}$. Historically, endoscopic third ventriculostomy (ETV) always seemed to be a promising technique and can be considered nowadays a standard procedure for obstructive hydrocephalus ${ }^{6,7}$. However, data published in the medical literature is both extensive and conflicting when they come to the role of patients' age and etiology of the hydrocephalus in the success rate (SR) of endoscopic procedures ${ }^{6,8-18}$.

In this study, we present the results of neuroendoscopic operations performed in children during the past ten years in the same institution.

${ }^{1}$ Division of Pediatric Neurosurgery of the Department of Surgery and Anatomy, University Hospital, Ribeirão Preto Medical School, University of São Paulo (USP), Ribeirão Preto SP, Brazil;

${ }^{2}$ Division of Stereotactic and Functional Neurosurgery of the Department of Neurosurgery, University Hospital Freiburg, Freiburg im Breisgau, Germany. Correspondence: Ricardo Santos de Oliveira; Department of Surgery and Anatomy, University Hospital, Ribeirão Preto Medical School, University of São Paulo; 14049-900 Ribeirão Preto SP - Brasil; E-mail: rsoliveira@hcrp.fmrp.usp.br 


\section{METHODS}

Between 2000 and 2010, 200 neuroendoscopic procedures were performed in 177 patients in the same institution by the senior author (R.S.O) for the treatment of hydrocephalus in patients under 18 years old. A rigid GAAB Karl Storz ${ }^{\circledR}$ neuroendoscope (Tuttlingen, Germany) equipped with a $n^{\circ} 8$ French diameter Hopkins rod lens system, a $0^{\circ}$ fiber optic, a $\mathrm{n}^{\circ} 3$ French working channel and an irrigation channel was used. All procedures were performed free hand after the induction of general anesthesia.

Routine postoperative outpatient follow-up appointments were scheduled within one week and, then, one, three and every six months. Success was defined by the following criteria: when no further intervention was required to treat hydrocephalus and the absence of signs or symptoms of raised intracranial pressure.

Data were analyzed with the Fisher test or a chi-square test to determine whether each factor was correlated with the success of the endoscopic procedure for categorical data; $p<0.05$ values were considered significant. The ratios of children requiring permanent postoperative shunts or further surgical interventions in the different subgroups were compared. The factors were grouped by patient age at surgery, underlying pathology, type of endoscopic procedure and postoperative complications.

The length of hospitalization and the learning curve related to the endoscopic approach were also analyzed.

\section{Group classification}

These patients fell into three groups. In Group A, 26 patients (mean age $4.8 \pm$ standard deviation (SD) 0.86 months) were under six months of age; in Group B, 25 patients were between six months and one year of age (mean age 7.4 \pm 1.02 months); and in Group C, 115 patients were older than one year of age (mean age $5.8 \pm 1.09$ years).

\section{RESULTS}

A total of 177 patients were studied. There were 78 male patients (44\%) and 99 female patients (56\%) ranging in age from 11 days to 18 years (mean age $5.1 \pm 1.06$ years). The mean follow-up period was 65 months (ranging from 10 months to 9 years).

The etiology of hydrocephalus was as follows: out of the 177 patients, cystic malformations were found in $45(25 \%)$, tumors in 40 (23\%), aqueductal stenosis (AS) in 33 (19\%), cerebral malformation in $30(17 \%)$, meningitis or ventriculitis in $8(5 \%)$, intraventricular hemorrhage in $6(3 \%)$, isolated ventricle in $3(2 \%)$ and other causes in 12 out of 177 (7\%) patients.

In 114 patients (64\%), ETV was performed as a single and straightforward procedure. In 29, (16\%) endoscopic cyst fenestration was performed. In 18 (10\%), two procedures were associated (i.e. ETV + cyst fenestration), in 11 (6\%) a ventricular catheter was placed guided by endoscopy and five patients (2\%) underwent ETV + tumor biopsy. The basic indication for endoscopic-assisted catheter placement was complex multiloculate hydrocephalus. Six of these patients were younger than six months and seven were pre-term children.

Sixty-six procedures $(33 \%)$ were performed in patients under one year of age. In 166 patients, the main goal of the endoscopic intervention was to restore the cerebrospinal fluid (CSF) flow pathways.

\section{Age group and SR}

The overall SR for CSF circulation restoration was 77\% (127/166). According to the age group, we observed a $46 \%$ $(12 / 26)$ SR in Group A; 68\% (17/25) in Group B, and 85\% (98/115) in Group C ( $\mathrm{p}=0.001$ ) (Fig 1$)$. Table 1 shows the distribution of patients with respect to their hydrocephalus etiology and SR per group of age according to the CSF restoration.

\section{Hydrocephalus etiology and SR}

In Group A, the etiology of hydrocephalus was related to complex cystic lesions or arachnoid cysts in 15 out of 26 (58\%) cases, whereas brain or spinal malformations (such as spinal dysraphism, Dandy Walker, Chiari malformation) were noted in four (15\%), and hemorrhage and ventriculitis in two cases (3.8\%). AS was observed in five patients (19\%).

Out of the 25 patients in Group B, cystic lesions were found in $6(24 \%)$, malformations in $5(20 \%)$, AS in $4(16 \%)$, posterior fossa tumors in $3(12 \%)$, hemorrhage in $2(8 \%)$, and infection in only one case. In Group C, an obvious predominance of pure obstructive hydrocephalus (i.e. posterior fossa tumors and AS) was observed in comparison to the other groups (19\% (5/26), $28 \%(7 / 25)$ and $53 \%(61 / 115)$ respectively ( $\mathrm{p}=0.002)($ Fig 2$)$.

The overall analysis according to etiology showed a success rate of $88.1 \%$ (29/33) in AS, 83\% (33/40) in hydrocephalus associated to posterior fossa tumors and $74 \%(32 / 43)$ in cystic lesions. Lower success rates were observed in cases of

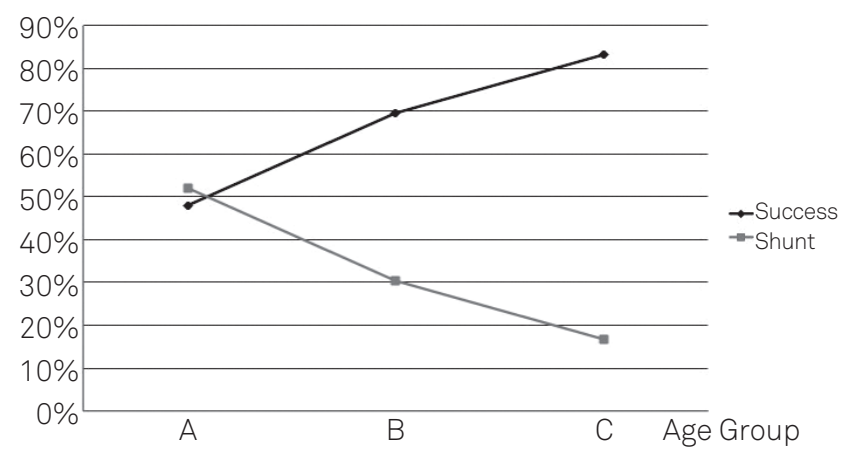

Group A: <6 months; Group B: 6 months-one-year old; Group C: older than one-year old $(p=0.001)$

Fig 1. Overall success rates according to age group. Line graph showing the correlation between age and success rate. 
Table 1. Cerebrospinal fluid circulation restoration procedures in 166 patients and success rate calculated according to the number of patients and procedures.

\begin{tabular}{|c|c|c|c|c|c|}
\hline \multirow{2}{*}{ Underlying pathology } & \multirow{2}{*}{$\mathrm{n}$} & \multicolumn{3}{|c|}{$\mathrm{SR}^{*}$} & \multirow{2}{*}{ Complication rat $\epsilon$} \\
\hline & & Group A & Group B & Group C & \\
\hline Tumor & 40 & 0 & $2 / 3(67 \%)$ & $31 / 37(84 \%)$ & $6 / 40(15 \%)$ \\
\hline Aqueductal stenosis & 33 & $3 / 5(60 \%)$ & $3 / 4(75 \%)$ & $22 / 24(92 \%)$ & $2 / 33(6 \%)$ \\
\hline Cystic lesions & 43 & $6 / 15(40 \%)$ & $5 / 6(83 \%)$ & $21 / 22(95 \%)$ & 4/43 (9\%) \\
\hline Brain malformations & 29 & $2 / 4(50 \%)$ & $3 / 5(60 \%)$ & $16 / 20(80 \%)$ & $5 / 29(17 \%)$ \\
\hline Hemorrhage/CSF infection & 9 & 0 & $1 / 3(33 \%)$ & $3 / 5(40 \%)$ & $3 / 9(33 \%)$ \\
\hline Other & 12 & 0 & $1 / 4(25 \%)$ & $6 / 7(86 \%)$ & 4/12 (33\%) \\
\hline
\end{tabular}

$\mathrm{n}$ : Values represent the number of patients (\%) unless otherwise stated; SR: success rate; CSF: cerebrospinal fluid; *assortment of the SR by "underlying pathology" did not reveal any statistically significant differences among these groups.

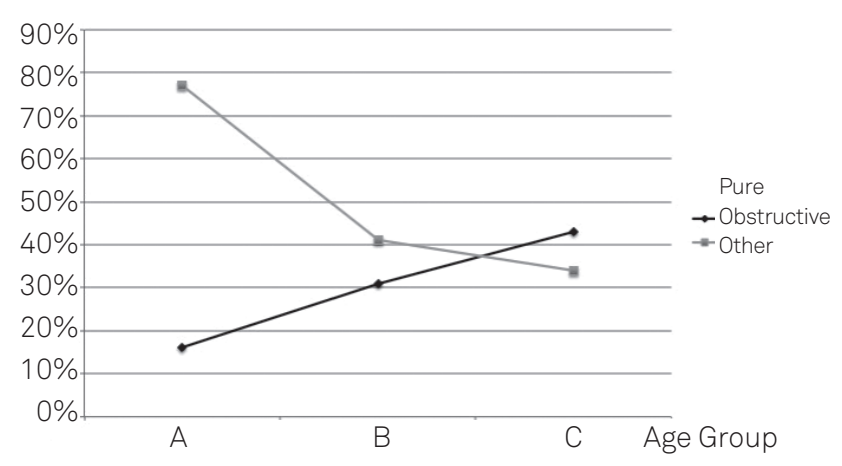

Group A: <6 months; Group B: 6 months-one-year old; Group C: older than one-year old $(p=0.002)$.

Fig 2. Etiology of hydrocephalus according to age group. Line graph showing the etiology of hydrocephalus in each age group. The etiology was grouped as pure obstructive (aqueductal stenosis and posterior fossa tumors) and other.

myelomeningocele, intraventricular hemorrhage and ventriculitis ( $\mathrm{p}=0.001$ ) (Fig 3).

Poorer outcomes were more frequent in premature infants compared to their full-term counterparts (56 and $77 \%$ of SR respectively, $\mathrm{p}=0.042$ ).

The overall success rate of ETV ranged from 33 to $86.4 \%$. ETV alone showed the best overall outcome, with $80 \%$ of good results (91/114), followed by $69 \%$ (20/29) success rate with cyst fenestrations. Among patients with AS, there was no statistical difference between the age groups: Group A - 60\% (3/5), Group B - 75\% (3/4) and Group C - 92\% (22/24) ( $\mathrm{p}=0.104)$.

The overall outcome of ETV in patients with previous intraventricular hemorrhage or infection was $44 \%$. There was no statistical significance between age groups $(\mathrm{p}=0.709)$. The mean length of time between ETV and failure was four months (ranging from 15 days to 9 months).

\section{Learning curve and complication rate}

The overall complication rate in this series was $11 \%$ (22/200). They included: intraventricular hemorrhage in $9 / 22$, infection in $7 / 22$ (three cases of meningitis, three of ventriculitis and one wound infection), CSF leakage in three cases, transient disfasia in two, and hypertensive pneumocephalus in one case. The mortality rate was $1 \%$. One patient developed severe

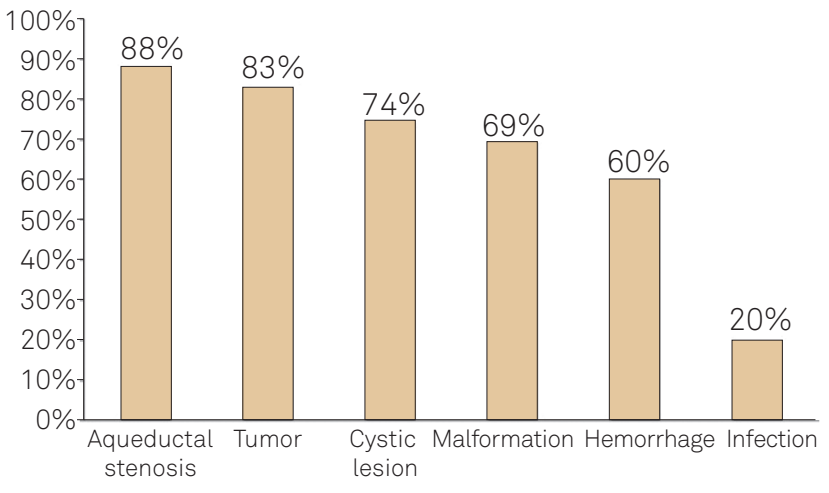

Fig 3. Overall success rates according to the etiology of hydrocephalus. Bar graph demonstrating the correlation between SR and the underlying pathology $(p=0.001)$.

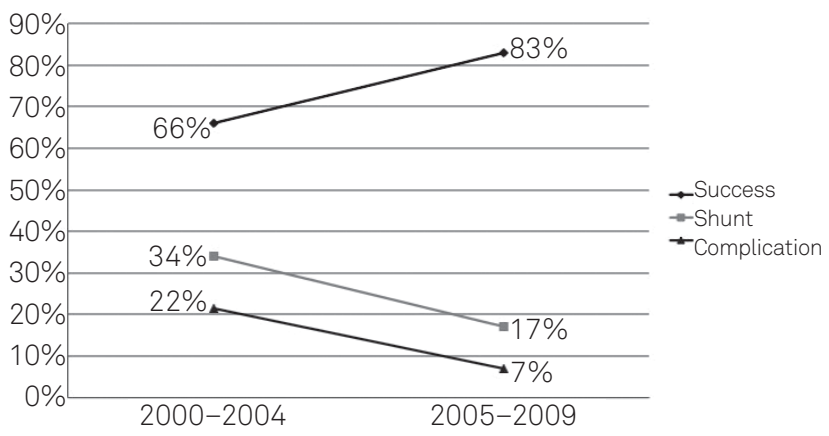

Fig 4. Learning curve. Line graph showing a synchronous improvement of the success rates and a remarkable decrease in the number of complications in two different time periods $(p=0.012)$.

ventriculitis and another patient died due to respiratory complications postoperatively. The complication rates in Groups A, B and C were 11.5, 12 and 13\%, respectively ( $\mathrm{p}=0.973$ ).

Analyzing the outcome in two different periods of time (between 2000-2004 and 2005-2010), an improvement in the success rate of neuroendoscopic procedures can be clearly seen (from $66(43 / 65)$ to $83 \%(84 / 101)(\mathrm{p}=0.012))$. We observed a significant complication rate reduction in the same period (21 and 7\%, p=0.006) (Fig 4).

The overall length of hospitalization was less than three days in $56 \%$ of the patients. 
Reoperations due to failure on the first attempt of the endoscopic procedure were needed in 23 patients. The SR in this group was $74 \%$ after a second procedure. Only 6 out of 23 patients required further operations (either endoscopy or shunt). Thirty-seven procedures (18\%) were performed in children that had been previously shunted. Previous shunt surgery was strongly correlated to failure of the endoscopic procedure $(\mathrm{p}=0.009)$.

\section{DISCUSSION}

Over the last few years, intracranial neuroendoscopy has found its place in pediatric neurosurgery. Current experience throughout the world shows that this treatment is a good alternative to shunts in many cases of cerebral disease, and particularly in obstructive hydrocephalus. ETV is considered to be a simple, fast and safe procedure in children ${ }^{15}$.

In this paper, we present a single-center experience with 200 consecutive endoscopic intracranial procedures performed in children. The overall success rate to restore CSF circulation was $77 \%$, and the absolute complication rate was $11 \%$. These data are in accordance with those reported in the literature ${ }^{3,19-21}$.

We reviewed only neuroendoscopic pediatric series published in the literature that had more than 100 cases (Table 2). The overall SR in those series ranged from 55.6 to $72 \%$ 3,19,21-27.

Despite technological advances in the last century concerning the management of hydrocephalus, the issue about timing of neuroendoscopy and its effectiveness in younger patients is still controversial ${ }^{5,12,15,16,20,28-31}$.

Also, there is no consensus regarding the appropriate age of patients to be treated with ETV. In most series, younger children were not included. Thus, some authors who have defended ETV suggest that it should be attempted only in children older than one year ${ }^{15,32}$. This may be explained by the poor CSF resorption capacity of newborn infants due to immaturity of arachnoid granulations. In addition, the anterior fontanel is widely open and the sutures can become splayed in infants, contributing to the maintenance of low intracranial pressure ${ }^{17,32-35}$.

On the other hand, some authors advocated that ETV has the same long-term results in children younger than six months when compared to older children and, therefore, patient age should no longer be considered a contraindication to using the technique; and in the event of delayed failure (usually, secondary to obstruction of the stoma) this can be often managed by repeating the procedure ${ }^{31,36}$.

The literature review showed that SR in children under six months of age ranged from 32 to $44.9 \%$, and in children older than one-year age it ranged from 56 to $71 \%$ (Table 2).

In our series, the etiology of hydrocephalus and patients' age group were both relevant factors predicting success. These results are in accordance with other authors ${ }^{15,36-38}$. ETV success rate among patients under one year with AS was $78 \%$, similar to the results among patients older than one year (90\%).

Moreover, intraventricular hemorrhage, myelomeningocele and previous CSF infection or shunt infection were strongly associated with failure of ETV in our series. Some authors reported similar results analyzing outcome and underlying pathology $\mathrm{y}^{15,28,30,33,39}$.

Another factor that influenced the outcome in this series was surgical experience ${ }^{21}$. We observed a remarkable reduction in the number of complications related to neuroendoscopic procedures in two subsequent time periods analyzed (from 20 to 11\%). Recently, Bouras and Sgouros ${ }^{40}$ published an extensive review of complications associated with ETV. Their analysis included 2.985 ETVs performed in 2.884 patients and they concluded that ETV can be regarded as a low-complication procedure, with an overall complication rate of $8.5 \%$, permanent morbidity rate of $2.4 \%$, mortality rate of $0.21 \%$, and delayed "sudden death" rate of $0.07 \%$. According to the literature, the overall complication rate ranged, in individual series, from 2 to 44.9\% (Table 2).

Table 2. Summary of data of the neuroendoscopic pediatric series published in the medical literature*.

\begin{tabular}{|c|c|c|c|c|c|c|c|}
\hline $\begin{array}{l}\text { Authors and year/ } \\
\text { reference }\end{array}$ & $\mathrm{n}$ & Overall SR & $\mathrm{SR}<2 \mathrm{yrs}$ old & $\mathrm{SR}<1 \mathrm{yr}$ old & $\mathrm{SR}<6$ mos old & $\begin{array}{c}\text { Mean } \\
\text { follow-up (mos) }\end{array}$ & $\begin{array}{c}\text { Complication } \\
\text { rate }\end{array}$ \\
\hline Bognar et al. (2005) & $221 / 247$ & $63 \%$ & N/A & $63 \%$ & $34 \%$ & 32 & N/A \\
\hline Warf et al. (2005) & $284^{\mathrm{a}}$ & N/A & N/A & $47 \%$ & N/A & 19 & $\sim 2 \%$ \\
\hline Peretta et al. (2006) 21 & $450 / 495$ & N/A & N/A & N/A & N/A & 62 & $8.1 \%$ \\
\hline Oertel et al. (2009) ${ }^{3}$ & $126 / 134$ & $72 \%(81 / 112)$ & $56 \%(15 / 27)$ & N/A & N/A & $12-72$ & $\sim 22 \%$ \\
\hline Kulkarni et al. (2009) ${ }^{16}$ & $618^{b}$ & $67 \%(305 / 455)$ & N/A & $64.1 \%$ & $44.9 \%$ & $>6$ & N/A \\
\hline Warf et al. $(2010)^{27}$ & 1406 & $55.6 \%(388 / 979)$ & $58 \%(64 / 109)$ & $41 \%(60 / 146)$ & $34 \%(143 / 421)$ & $6-36$ & $N / A$ \\
\hline Sacko et al. $(2010)^{25}$ & 165 & $66 \%(109 / 165)$ & $71 \%(27 / 38)$ & $N / A$ & $32 \%(7 / 22)$ & $47(6-106)$ & $\sim 10 \%$ \\
\hline Naftel et al. (2011) ${ }^{24}$ & $136 / 151$ & $68 \%(93 / 136)$ & N/A & N/A & N/A & 39.4 & $9.3 \%$ \\
\hline Durnford et al. (2011)22 & $181^{a}$ & $64.5 \%$ & $\mathrm{~N} / \mathrm{A}$ & $\mathrm{N} / \mathrm{A}$ & $\mathrm{N} / \mathrm{A}$ & 28.6 & $6 \%$ \\
\hline
\end{tabular}

*Only pediatric series with more than 100 neuroendoscopic cases were included; SR: success rates; N: values represent number of patients/procedures; NA: data not available; ETV: endoscopic third ventriculostomy; yr: year; mos: months; ${ }^{\mathrm{a}}$ : ETV alone; ${ }^{\mathrm{b}}$ : Multicentric analysis. 
In the present series, reoperations due to failure of the first attempt of endoscopic procedure were observed in $11.5 \%$ of cases. The success rate was $74 \%$ after a second procedure. These results are similar to other series ${ }^{31}$.

Therefore, despite the fact that some patients suffering from reocclusion of the stoma might have to undergo shunting, several authors consider well worth trying to repeat ETV ${ }^{31,36}$.

In conclusion, neuroendoscopic techniques provide very good results for a wide number of indications in children.
Tumor-related CSF circulation problems and AS seem to be particularly well suited to neuroendoscopic treatment regardless of the patient's age. Intraventricular hemorrhage, previous CNS infection and myelomeningocele showed very high failure rate in infants under six months of age. The reduction of complication rates occurred as a result of accumulated surgical experience over the years. Every effort should be made to optimize the selection of surgical candidates on the basis of the underlying pathology.

\section{References}

1. Dandy WE, Blackfan KD. An experimental and clinical study on internal hydrocephalus. JAMA 1913;61:2216-2217.

2. Cipri S, Gambardella G. Neuroendoscopic approach to complex hydrocephalus. Personal experience and preliminary report. $J$ Neurosurg Sci 2001;45:92-96.

3. Oertel JMK, Gaab M, Schroeder HW, Baldauf J. Endoscopic options in children: experience with 134 procedures. J Neurosurg Pediatr 2009;3:81-89.

4. EnchevY,OiS. Historical trends of neuroendoscopic surgical techniques in the treatment of hydrocephalus. Neurosurg Rev 2008;31:249-262.

5. Rekate HL. Selecting patients for endoscopic third ventriculostomy. Neurosurg Clin N Am 2004;15:39-49.

6. O'Brien DF, Javadpour M, Collins DR, Spennato P, Mallucci CL. Endoscopic third ventriculostomy: an outcome analysis of primary cases and procedures performed after ventriculoperitoneal shunt malfunction.J Neurosurg 2005;103:393-400.

7. Oertel JKM, Schroeder H, Gaab MR. Third Ventriculostomy for treatment of hydrocephalus: results of 271 procedures. Neurosurg Quarterly 2006;16:24-31.

8. Balthasar AJ, Kort H, Cornips EM, Beuls EA, Weber JW, Vles JS. Analysis of the success and failure of endoscopic third ventriculostomy in infants less than 1 year of age. Childs Nerv Syst 2007;23:151-55.

9. Cohen AR. Prediction, with restriction. J Neurosurg Pediatr 2010;6:307-309.

10. Di Rocco C, Massimi L, Tamburrini G. Shunts vs endoscopic third ventriculostomy in infants: are there different types and/or rates of complications? A review. Childs Nerv Syst 2006;22:1573-1589.

11. Drake JM. Endoscopic third ventriculostomy in pediatric patients: the Canadian experience. Neurosurgery 2007;60:881-886.

12. Etus V, Ceylan S. Success of endoscopic third ventriculostomy in children less than 2 years of age. Neurosurg Rev 2005;28:284-288.

13. Hellwig D, Grotenhuis JA, Tirakotai W, et al. Endoscopic third ventriculostomy for obstructive hydrocephalus. Neurosurg Rev 2005;28:1-38.

14. Kadrian D, van Gelder J, Florida D, et al. Long-term reliability of endoscopic third ventriculostomy. Neurosurgery 2005;56:1271-1278.

15. Koch D, Wagner W. Endoscopic third ventriculostomy in infants of less than 1 year of age: which factors influence the outcome? Childs Nerv Syst 2004;20:405-441.

16. Kulkarni AV, Drake JM, Mallucci CL, Sgouros S, Roth J, Constantini S, Canadian Pediatric Neurosurgery Study Group. Endoscopic third ventriculostomy in the treatment of childhood hydrocephalus. J Pediatr 2009;155:254-259.

17. Wagner W, Koch D. Mechanisms of failure after endoscopic third ventriculostomy in young infants. J Neurosurg 2005;103:43-49.

18. Yadav YR, Jaiswal S, Adam N, Basoor A, Jain G. Endoscopic third ventriculostomy in infants. Neurol India 2006;54:161-163.
19. Bognar L, Markia B, Novak L. Retrospective analysis of 400 neuroendoscopic interventions: the Hungarian experience. Neurosurg Focus 2005;19:E10

20. Gorayeb RP, Cavalheiro S, Zymberg ST. Endoscopic third ventriculostomy in children younger than 1 year of age. J Neurosurg 2004;100:427-429.

21. Peretta P, Ragazzi P, Galarza M, et al. Complications and pitfalls of neuroendoscopic surgery in children. I Neurosurg Pediatr 2006;105:187-193.

22. Durnford AJ, Kirkham FJ, Mathad N, Sparrow OC. Endoscopic third ventriculostomy in the treatment of childhood hydrocephalus: validation of a success score that predicts long-term outcome. $J$ Neurosurg Pediatr 2011;8:489-493.

23. Kulkarni AV, Drake JM, Kestle JR, Mallucci CL, Sgouros S, Constantini S; Canadian Pediatric Neurosurgery Study Group. Predicting who will benefit from endoscopic third ventriculostomy compared with shunt insertion in childhood hydrocephalus using the ETV Success Score. J Neurosurg Pediatr 2010;6:310-315.

24. Naftel RP, Reed GT, Kulkarni AV, Wellons JC. Evaluating the Children's Hospital Alabama endoscopic third ventriculostomy experience using the endoscopic third ventriculostomy success score. J Neurosurg Pediatr 2011;8:494-501.

25. Sacko O, Boetto S, Lauwers-Cances V, Dupuy M, Roux FE. Endoscopic third ventriculostomy: outcome analysis in 368 procedures. J Neurosurg Pediatr 2010;5:68-74.

26. Warf BC. Comparison of endoscopic third ventriculostomy alone and combined with choroid plexus cauterization in infants younger than 1 year of age: a prospective study in 550 African children. J Neurosurg Pediatr 2005;103:475-481.

27. Warf BC, Mugamba J, Kulkarni AV. Endoscopic third ventriculostomy in the treatment of childhood hydrocephalus in Uganda: report of a scoring system that predicts success. J Neurosurg Pediatr 2010;5:143-148.

28. Elgamal E, El-Dawlatly AA, Murshid WR, El-Watidy SM, Jamjoom ZA. Endoscopic third ventriculostomy for hydrocephalus in children younger than 1 year of age. Childs Nerv Syst 2011;27:111-116.

29. Fritsch MJ, Kienke S, Ankermann T, Padoin M, Mehdorn HM. Endoscopic third ventriculostomy in infants. J Neurosurg 2005; 103:50-53.

30. Kim SK, Wang KC, Cho BK. Surgical outcome of pediatric hydrocephalus treated by endoscopic III ventriculostomy: prognostic factors and interpretation of postoperative neuroimaging. Childs Nerv Syst 2000;16:161-169.

31. Siomin $\mathrm{V}$, Weiner $\mathrm{H}$, Wisoff $\mathrm{J}$, et al. Repeat endoscopic third ventriculostomy: is it worth trying? Childs Nerv Syst 2001;17:551-555.

32. Hopf NJ, Grunert P, Fries G, Resch KD, Perneczky A. Endoscopic third ventriculostomy: outcome analysis of 100 consecutive procedures. Neurosurgery 1999;44:795-806. 
33. Jones RF, Kwok BC, Stening WA, Vonau M. Third ventriculostomy for hydrocephalus associated with spinal dysraphism: indications and contraindications. Eur J Pediatr Surg 1996;6:5-6.

34. Oi S, Abbott R. Loculated ventricles and isolated compartments in hydrocephalus: their pathophysiology and the efficacy of neuroendoscopic surgery. Neurosurg Clin N Am 2004;15:77-87.

35. Oi S, Di Rocco C. Proposal of "evolution theory in cerebrospinal fluid dynamics" and minor pathway hydrocephalus in developing immature brain. Childs Nerv Syst 2006;22:662-669.

36. Cinalli G, Sainte-Rose C, Chumas P, et al. Failure of third ventriculostomy in the treatment of aqueductal stenosis in children. J Neurosurg 199;90:448-454.
37. Baldauf J, Gaab MR, Schroeder H. Endoscopic third ventriculostomy in children younger than 2 years of age. Childs Nerv Syst 2007;23:623-626.

38. Beems T, Grotenhuis JA. Is the success of endoscopic third ventriculostomy age-dependent? An analysis of the results of endoscopic third ventriculostomy in children. Childs Nerv Syst 200;218:605-608.

39. Elbabaa S, Steinmetz M, Ross J, Moon D, Luciano M. Endoscopic third ventriculostomy for obstructive hydrocephalus in the pediatric population: evaluation of outcome. Eur $\mathrm{J}$ Pediatr Surg 2001;11:S52-S54.

40. Bouras T, Sgouros S. Complications of endoscopic third ventriculostomy. J Neurosurg Pediatr 2011;7:643-649. 